\title{
Therapeutics
}

\section{A needs based intervention for patients with schizophrenia and their carers reduced relapse and carer needs}

Barrowclough C, Tarrier N, Lewis S, et al. Randomised controlled effectiveness trial of a needs-based psychosocial intervention service for carers of people with schizophrenia. Br J Psychiatry 1999 Jun;174:505-11.

QUESTION: In patients with schizophrenia, does a 24 week needs based family intervention (compared with family support alone) reduce relapse and relieve carer problems?

\section{Design}

Randomised (allocation concealed*), blinded (outcome assessor)*, controlled trial.

\section{Setting}

2 mental health units in Manchester, UK.

\section{Patients}

77 patients who were $18-65$ years of age (mean age $36 \mathrm{y}$, $65 \%$ men) with a clinical $I C D$ - 10 diagnosis of schizophrenia, schizoaffective disorder, or delusional disorder. Other inclusion criteria were schizophrenia for $\geqslant 2$ years (mean duration $12.7 \mathrm{y}$ ), $\geqslant 1$ relapse of psychotic symptoms requiring hospital admission in the previous 2 years (mean number of admissions to hospital 7.0), and $\geqslant 10$ hours each week of contact with their primary carer. Exclusion criteria were organic brain disease or learning disability. Each patient was entered into the study with 1 primary carer (mean age 53 y, 71\% women). Post-test assessments were completed by $90 \%$ of patient carer pairs.

\section{Intervention}

39 patient carer pairs were allocated to receive family support plus a needs based psychosocial intervention service and 38 were allocated to family support alone. A family support worker provided information, benefits advice, advocacy, emotional support, and practical help. The psychosocial interventions were based on carer needs assessed using the relatives' version of the Cardinal Needs Schedule. Interventions were of 3 types: problem solving techniques, cognitive behavioural interventions with families, and cognitive behavioural interventions with patients with psychosis.

\section{Main outcome measures}

Frequency of relapses in patients and change in number of cardinal needs for carers.

\section{Main results}

A trend existed for fewer patients in the psychosocial intervention group to have $\geqslant 1$ relapse than patients in the control group (Fisher's exact test $\mathrm{p}=0.056$ \{near exact $p=0.043\} \dagger)$ (table). Intervention group patients spent fewer days in relapse than did control group patients (446 v $1077 \mathrm{~d}, \mathrm{p}=0.048$ ). Among carers, the number of cardinal needs decreased to a greater extent in the intervention group than in the control group

Needs based family intervention plus support (FIS) v family support alone (FS) for schizophrenia at 6 months

\begin{tabular}{|c|c|c|c|c|}
\hline Outcome & FIS & FS & $\operatorname{RRR}(95 \% \mathrm{Cl})$ & NNT (Cl) \\
\hline$\geqslant 1$ relapse & $24 \%$ & $46 \%$ & $49 \%$ (3 to 74$)$ & 5 (3 to 99 ) \\
\hline
\end{tabular}
article. (median change score $2 v 0, \mathrm{p}=0.018)$. A decrease in the number of problems was also seen (median change score $3 v 2, \mathrm{p}=0.043)$.

\section{Conclusion}

In patients with schizophrenia spectrum disorders, a 24 week needs based family intervention showed a trend toward reduced relapse and a significant reduction in carer needs and problems.

*See glossary.

tp Value calculated from data in article.
Source of funding: National Health Service Executive North West.

For correspondence: $\mathrm{Dr}$ C Barrowclough, Academic Department of Clinical Psychology, Mental Health Unit, Tameside General Hospital,

Ashton-under-Lyne, Lancashire OL6 9RW UK. Fax $+44(0) 161$

3315050 .

\section{COMMENTARY}

Family interventions in schizophrenia, designed to reduce expressed emotion or otherwise improve coping skills, were developed based on the finding that relapse rates were higher among patients living with relatives than in those moving to hostels. ${ }^{1}$ Despite clear systematic review evidence of efficacy, ${ }^{2}$ these interventions are not yet a standard component of schizophrenia treatment.

Barrowclough et al, through a well designed, randomised, controlled trial of a particular family intervention in 2 UK National Health Service hospital trusts, address concerns about whether academic findings translate into clinical gains. Recruitment and patient progress are clearly described. Initial assessments, outcome measures, and analysis are appropriate.

The results support previous findings, ${ }^{2}$ the treatment group showing a substantial reduction in relapse and identified carer need, but the parts of the intervention programme that are effective are not identified. The stability of other outcome measures was not surprising because patients were relatively settled at outset. More disappointing, especially given the researchers' experience and enthusiasm, was the poor engagement of carers and key workers.

Family intervention is advocated by the UK government ${ }^{3}$ and answers supporters requests for greater involvement in patient care. No clear evidence yet exists about the relative efficacy of different family interventions, hence anyone planning to establish a programme lacks an evidence base to guide their choice of intervention. Programmes are labour intensive (in this study a median of 14 sessions) and require specialised staff training. Services would also need to develop and maintain a programme infrastructure. Many potential patients will not meet inclusion criteria or will decline to participate, hence these interventions may be most effective in services with a large population base. Savings may be small unless hospital admissions are substantially reduced.

Clinicians cannot afford to ignore the weight of evidence about the efficacy of family interventions. The straightforward interventions described by Barrowclough $e t a l$ are a suitable basis for such a service.

Steve Brown, MBBS, MRCPsych Royal South Hants Hospital Southampton, UK

1 Brown GW, Carstairs GM, Topping G. Post-hospital adjustment of chronic mental patients. Lancet 1958;ii:685-9.

2 Pharoah FM, Mari JJ, Streiner D. Family intervention for schizophrenia. (Cochrane Review, latest version 24 February 1999.) In Cochrane Library. Oxford: Update Software.

3 Department of Health. Modernising mental health services. London: HMSO; 1998. http://www.doh.gov.uk/nsf/mentalh. htm. 